\title{
Blockchain-Based Consumer Stock Ownership Plans (CSOP) As a Catalyst For Impact Investments in Sustainable Energy Infrastructure
}

\author{
Martin Fortkort ${ }^{*}$ (1), Sebastian Finke, and Semih Severengiz(1) \\ Sustainable Technologies Laboratory, Bochum University of Applied Sciences, Bochum, Germany
}

Received: 28 June 2021 / Received in final form: 10 October 2021 / Accepted: 10 October 2021

\begin{abstract}
The challenges of climate change and lack of access to electricity create an urgent need for sustainable energy infrastructure projects in developing countries. Sustainable impact investment schemes are a potential catalyst to finance such projects. A particularly sustainable financing option can be the Consumer Stock Ownership Plan (CSOP), combining the interests of impact investors and the local population. The infrastructure, e.g., a sustainable energy mini-grid, is owned by the investors and the local population at the same time. The population thus benefits from access to electricity and active participation in energy supply, while investors benefit from new forms of investment with social impact. However, CSOP is a complex model that requires a secure organisation and infrastructure. By integrating blockchain technology, the organisational structure of the model can be automatically managed via smart contracts, reducing the influence of intermediary institutions. This makes the investment more secure, transparent, and efficient. The paper outlines a concept for an impact investment CSOP model coupled with blockchain-based smart contracts as a scalable solution for sustainable energy infrastructure projects, in which the ownership of the infrastructure is transferred to the community over time. The model considers all relevant parameters before, during and after the life cycle of the energy infrastructure and aims to secure a sustainable long-term energy supply in developing countries through self-administration, educational measures, and participation of all stakeholders. In the next step, the concept developed in this paper will be applied to an energy infrastructure pilot project at the Don Bosco Solar and Renewable Energy Centre in Ghana.
\end{abstract}

\section{Introduction}

The need for the transition of energy systems from fossil fuels to renewable energies (RE) is reflected in the policy targets of governments around the globe. Immense efforts are needed to decelerate and limit global warming, of which the energy sector is a major contributor, emitting $73.2 \%$ of global greenhouse gases [1]. Therefore, a rapid transition to renewable energy for electricity, but also for heating, cooling, transportation and for the industry, is of utter importance to mitigate climate change [2]. Financial, technical, and social innovations are needed to shape a transformation of the energy system towards a sustainable path. Around the world, this need has created business models with a focus of involving citizens. This includes participation models that give property rights to consumers in renewable energy projects in a local or regional area. Advantages of citizen involvement include more

\footnotetext{
* e-mail: martin.fortkort@stud.hs-bochum.de
}

participation, the creation and mobilisation of local social capital as well as the potential to provide local consumers with electricity and heat at lower costs. In addition, small, decentralised citizen-related energy projects may act as forerunners of a more sustainable society. Assistance and information on the adoption of environmentally friendly technologies may change individual consumption patterns to improve energy efficiency by raising the awareness of individual electricity consumption.

The (co-)ownership of consumers in renewable energies may act as an essential cornerstone for the overall success of the energy transition. One model to achieve that is the Consumer Stock Ownership Plan (CSOP). It was developed in the 1950s by the US lawyer and investment banker Louis O. Kelso to give people without sufficient investment funds the opportunity to obtain productive capital [3]. Regardless, the CSOP model presents wide-ranging challenges, primarily due to the complexity of value and share transfers. This approach has been tested, implemented and researched within various projects, such as the 
SCORE project [4], which is funded by the European Union (EU)'s Horizon 2020 research and innovation program. As this project is aimed at European countries only, adaptations to the model for transferability to developing countries will be discussed in this paper. For example in Africa, according to the International Renewable Energy Agency (IRENA) there are numerous initiatives that address energy issues, but often lack participation of civil society while showing high levels of private-sector involvement [5]. Furthermore, the authors of this paper are not aware of any CSOP-related project integrating blockchain technology to date.

Combined with blockchain technology, the CSOP model could be an attractive option to provide sustainable energy infrastructure for developing countries by facilitating processes and providing efficient and universal tools to foster investments while enabling active participation of civil society. The implementation of the specific impact investment models presented in this paper is meant to contribute to the 17 Sustainable Development Goals (SDGs) promulgated in 2015 by the United Nations (UN) [6]. The specific contributions are cross-sectoral, having an impact on a wide range of different SDGs, for example, SDG 4 (Quality Education), SDG 7 (Affordable and Clean Energy) and SGD 9 (Industry, Innovation and Infrastructure). Investments in RE infrastructure can also have synergy effects on a broader number of SDGs [7].

The aim of this paper is to develop a new model combining CSOP and blockchain technology, which in the form of a holistic approach offers possibilities for a futureoriented impact investment applicable universally for different regions on the globe. It includes the investment, implementation, education, utilisation, and maintenance of regenerative energy infrastructure. It can function as a multiplier in less developed countries and have major economies of scale due to the possibility of a universal application in a broad range of projects in the context of renewable energy infrastructure. The theoretical framework developed in this work can function as a catalyst for sustainable energy infrastructure projects. It will be tested at the Don Bosco Solar and Renewable Energy Centre in Tema, Ghana and is to be incorporated into the MoNaL project funded by the German Federal Ministry for Environment (BMU) within the program "Export Initiative Environmental Technologies". Part of the project is the implementation of a smart RE mini-grid for the electricity supply of light electric vehicles such as electric mopeds and cargo pedelecs (LEV) [8].

\section{Current status - CSOP for impact investment}

In recent years, impact investment has played an important role in the investment landscape and can contribute to achieving the Sustainable Development Goals (SDGs). Financial returns and social/environmental outcomes as the main interests of impact investors can be important factors in private sector investment, which is envisaged to account for more than half of the required 1.4 trillion US dollars annually needed for financing the achievement of the SDGs in low- and lower-middle-income countries [9]. Taking sub-Saharan Africa as an example, investments in energy generation capacities are needed due to increasing demand in electricity as well as undercapacity power supply. According to the World Energy Outlook 2020 [10], 580 million people in sub-Saharan Africa had no access to electricity in 2019, and the number is likely to increase in 2020. The electricity access in this region is only $45 \%$, while the world average is $89 \%$.

The availability of energy supply is an important driver of economic development, as it leads to more involvement of citizens in economic activities, allowing them to increase their living standards [11]. The electricity supply functions as an indicator for a country's living standards and for important services such as the quality of national healthcare facilities [12]. The CSOP as a possible financing model for energy infrastructure projects in developing countries is presented in the following.

\subsection{Methodology}

This paper deals with the conceptualisation and enhancement of Consumer Stock Ownership Plans (CSOPs). The concept of CSOPs is presented below and enhanced in the paper by integrating blockchain technology and the presentation of a next-generation CSOP model. CSOP is a financing technique using an intermediary corporate instrument facilitating the involvement of individual investors through a trust. It is a type of investment transaction that can use external funding to take advantage of financial leverage. The goal of the CSOP business model is to create a stock-owned operating company (OC) that manages the object of the investment, which can be a renewable energy infrastructure. At the same time, it is owned by consumers together with other coinvestors. All profits are distributed according to the shareholding among consumers and co-investors.

The CSOP model differs from other approaches, such as a cooperative, mainly in its governance model. It was developed to enable scalable investments and is open to coinvestments by local partners such as municipalities or energy providers. As opposed to conventional investment programs, where savings or assets are needed, consumers can repay their share of the acquisition loan from the future income of the investment [13].

In addition, compared to cooperatives a CSOP model offers reduced participation costs and also the option of hiring external management to relieve consumers of this task. CSOPs are designed for regulated markets with certain prices, regulated market access and long-term relationships between products and consumers. The energy market fits that description, which makes the CSOP trust a viable option for renewable energy plants, e.g., based on solar or wind energy [3].

By implementing CSOPs for energy infrastructure, especially smaller communities in rural areas may benefit in the form of access and additional income. Low-income households, which normally do not have the savings required for traditional investment programs, can repay their share of the acquisition loan from the future income of the investment [13]. An important precondition for this is 


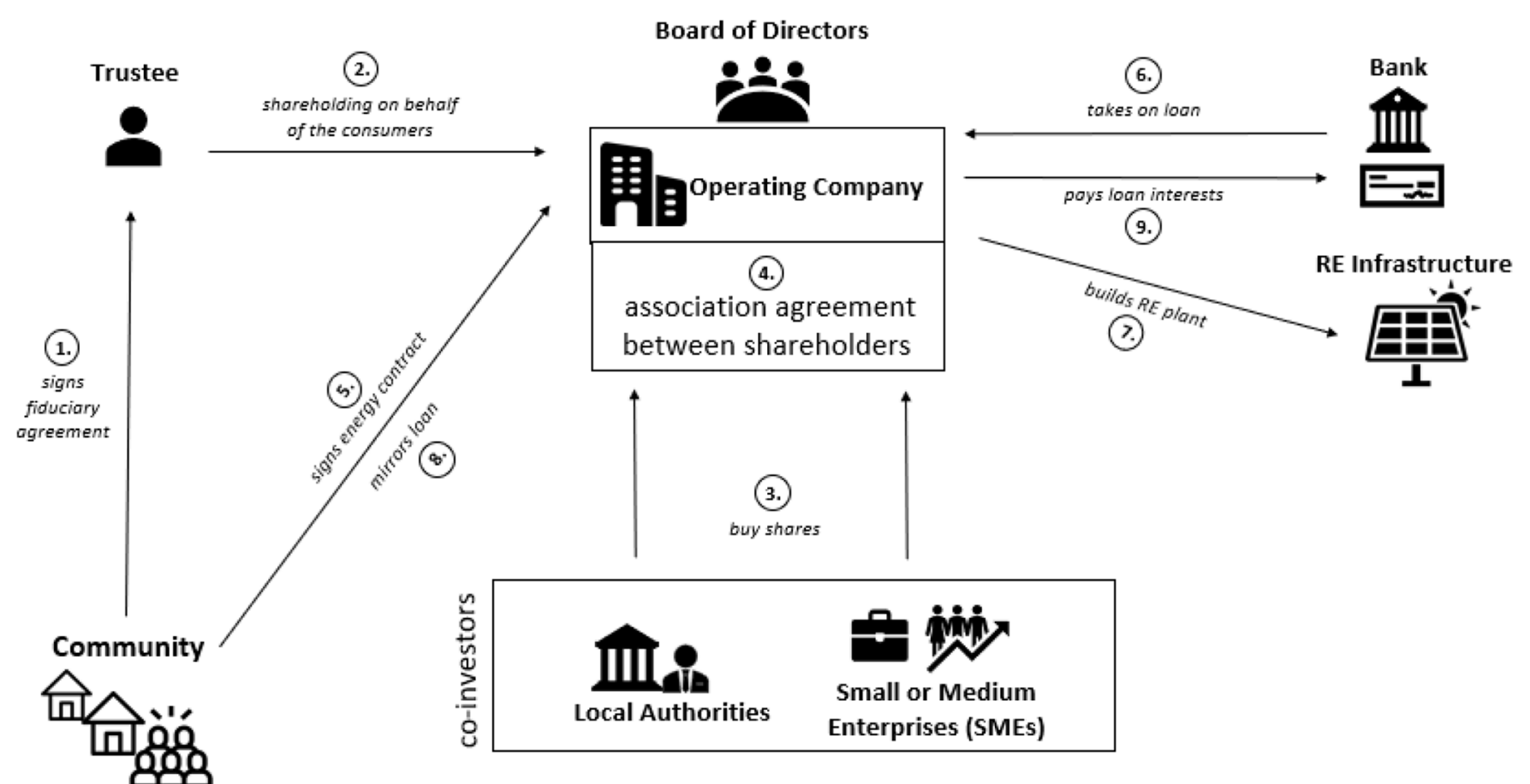

Fig. 1. CSOP structure and organisation (own figure based on Lowitzsch [13]).

that the electricity is used for generating income, for example by using it for production issues. The process for the formation of a CSOP operating company as well as the organisation and structure of a CSOP is described in Figure 1. In a first step, the community signs a fiduciary agreement to implement a trustee, who is responsible for the shareholding on behalf of the consumers (step 2). Coinvestors like local authorities or small and medium enterprises (SMEs) buy shares (step 3) and form a board of directors with the trustee and the operating company legitimised by an association agreement (step 4) between the shareholders. After an energy contract between the operating company and the community is signed (step 5), the company takes on a loan (step 6) and constructs the RE infrastructure (step 7). The loan is mirrored by the community (step 8) and paid back (step 9) by the income generated by the RE infrastructure.

\subsection{Blockchain-integrated CSOP model}

Blockchain technology is an efficient tool for process optimisation and can create various additional values for the implementation of a CSOP model. This technology can have a wide range of effects on processes, as well as on governance structures, which can significantly change the distribution of tasks between process participants. These advantages could help to overcome specific challenges in the CSOP model, for example, the complexity of share and value transfer and the multidimensional interactions between the actors in the system. In the following, the basics of the technology are described before considering a possible combination of the CSOP model with blockchain technology.

\subsubsection{Blockchain technology}

According to Yaga et al. [14], blockchains can be defined as "distributed digital ledgers of cryptographically signed transactions that are grouped into blocks". The blocks are cryptographically linked to each other in a chain. When new blocks are added, modifying older blocks becomes nearly impossible. Conflicts in this system are resolved automatically by using established rules. Blockchain technology became widely known in 2009 when the Bitcoin cryptocurrency was launched. Since then, different blockchain ecosystems (e.g., Ethereum) have been developed. Today, the technology is available for a high number of applications.

Blockchain technology was initially developed as a platform for digital currencies. It is based on the principle of distributed ledgers and is said to have the potential to trigger disruptive changes in various industries, including the financial sector [15]. Besides the distributed ledger technology, smart contracts are a core element of blockchain technology, constituting the rules that govern the relation between the participants in the distributed ledger. In an application which requires the exchange of assets, a smart contract can serve as a wrapper which automatically moves value and executes terms that are established within the contract. Thus, smart contracts have the potential to automate law and statutes and improve government services efficiency and transparency [16].

Blockchain technology as an enabler for tracing assets and autonomously settling transactions while providing a secure, fault-tolerant and resilient model is considered to be a foundational technology, influencing existing and creating new business models [17]. In the following, the 


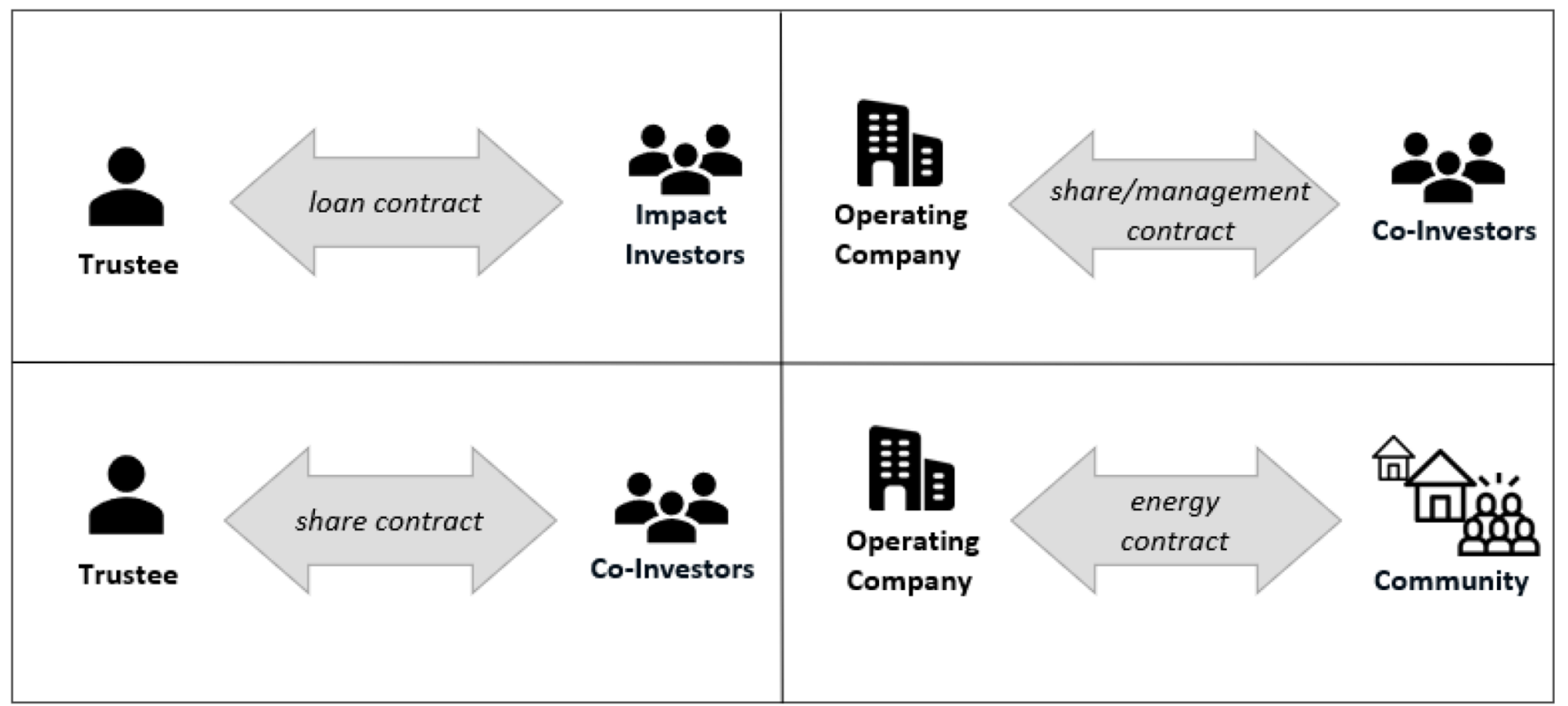

Fig. 2. Possibilities of individual smart contracts.

integration of blockchain technology into the CSOP model is described.

\subsubsection{Conceptual framework for blockchain integration}

Blockchain technology can be useful to improve important elements of the CSOP model. The CSOP presents wideranging challenges due to the complexity of value and share transfers. The role of the investors and the type of investment need to be considered. Blockchain technology enables decentralisation of transaction management, but also the automation of processes, regulations, and organisational principles. The transactions can be expanded by rules with smart contracts. They specify what is to be verified for a transaction and which follow-up activities are to be initiated.

The blockchain acts as a distributed data storage and irrevocably secures public and private data with all relevant information for the smart contract. The smart contract as an executing computer program checks the compliance of any action with the contents of the contract contained therein and legitimises the independent financial transactions when certain contractual conditions are fulfilled [18]. Figure 2 shows the possibilities of implementing smart contracts within the CSOP model. Individual kinds of arrangements between the actors regarding the loan, share/management, shares of the investment object and the energy distribution can be integrated in smart contracts. It should be noted that smart contracts alone can contain significant arrangements between different parties, but these may need to be supplemented by other legally binding classical contracts.

The main task of blockchain technology in a CSOP is to represent company shares and to make them transferable. Another important function is the management of the profit payout, which is based on the individual stakeholder amount of the company shares. Furthermore, the blockchain regulates the transfer of assets and the allocation of company shares. Therefore, before implementing a blockchain, the rules and procedures of a CSOP must be discussed and only converted into program code when a common consensus is achieved. It should also be noted that, if necessary, country and state regulations and laws should be converted into program code as a kind of restriction. An important possibility is also for the trustee to be replaced by a smart contract regulating the whole system because an intermediary would be obsolete. This could give the community more control over the process by directly involving their members instead of transferring responsibilities to a trustee. The possible implementation of smart contracts into the blockchain-integrated CSOP model is shown in Figure 3.

The smart contracts used in the blockchain act as a regulator for the CSOP. If predefined values are exceeded during the distribution of the assets, an external buy-in will be denied. Here, an example of a $33 \%$ limit for individuals and a $49 \%$ limit for external non-local investors can be used. The CSOP's smart contracts should implement these rules and regulate or even prevent purchases or sales in case of scenarios, in which for example the ownership percentage limits are exceeded.

Blockchain technology can also display ownership, with asset tokens as proof of ownership. For this, a legal framework in relation to conventional transfer of ownership via notary must be created. It is conceivable that the asset is recorded in its entirety in the register by a party acting as owner. The transfer of individual shares in the renewable energy infrastructure will be handled internally via blockchain. Asset tokens generated by blockchain technology must be regarded as a security that can be traded on the market. This perspective allows the assumption that there is a possibility that the price of the asset token could increase in value. 


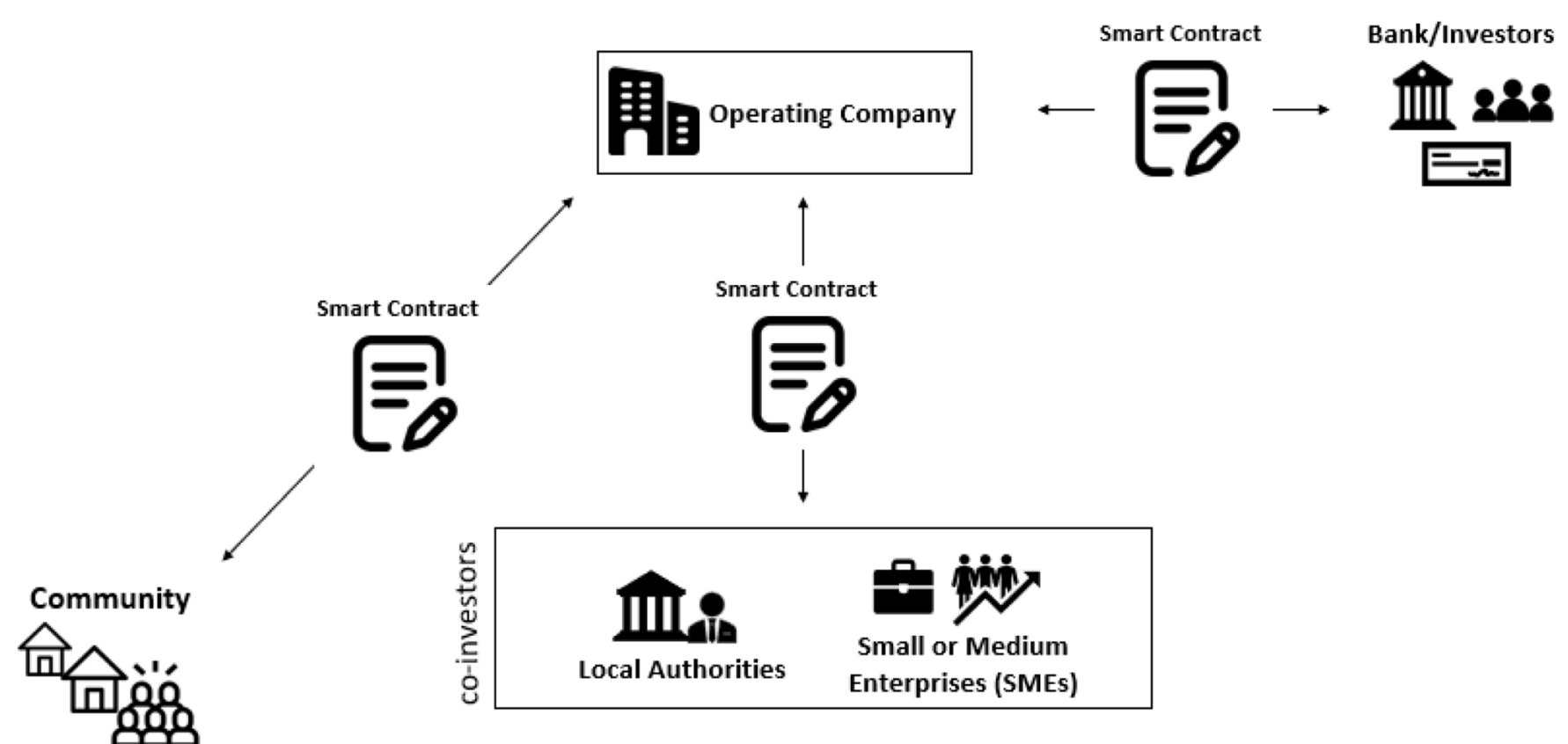

Fig. 3. Possible implementation of smart contracts.

A rising token price could be a significant advantage. Because the company shares are traded in the form of tokens in part on crypto and impact exchanges, the value could be created through the energy generated, but also through the price of the token which reflects the company shares. If this price is traded on these exchanges, the value of the tokens and the value of the entire asset can increase when demand is high. The agreed transfer of the company shares with simultaneous consumption of electricity is recorded in the form of tokens in the prosumer contract. In this case, the rising price of the token would increase the monetary income for all parties involved and especially for the consumers. By transferring company assets into tokens and trading with them, the CSOP model is further developed. With the new possibility of trading, economic efficiency can increase. The dependence on the market needs to be considered here and evaluated in a more indepth analysis.

In order to implement a business model or other forms of joint management such as the CSOP in a blockchain environment, various platforms are available which enable the implementation, programming and use of smart contracts. There are open-source solutions like the "Truffles Suit"-Platform, which is a smart contract creation platform for Ethereum [19], and solutions which are already applicated in the business environment, like those created by IBM and other vendors [20].

\section{Next generation CSOP for impact investment}

Based on the results of the research in the area of CSOP and blockchain, we have developed a model that combines the possibilities of blockchain technology with the requirements in the area of impact investment in relation to renewable energy infrastructures. The overall aim of the presented model is to provide access to clean energy for communities with a lack of access to energy and to guarantee a sustainable long-term use with numerous additional values for the community. Gaining infrastructure ownership by transferring the RE plant from the impact investors to the community maximizes participation and is the key aspect of the approach. The model is described in Figure 4 and will be explained in the following by its six central steps.

The key actor in this model is the RE company, providing information for the impact investors and placing the investment in a smart contract integrated into a blockchain ecosystem (step 1). The smart contract must contain all relevant information and regulations for the realisation of the project, for example ownership rules and the price for an asset token. A system comparable to a bond is installed in the smart contract of which investors can buy shares (asset tokens) of the RE infrastructure (step 2). One asset token is priced regarding to a calculation previously executed for the specific RE infrastructure project. The price includes different costs like the installation and operation costs of the plant, maintenance and education costs as well as interest rates for the impact investors. The sum is divided by the projected kilowatt hour of electricity production outcome of the RE plant during a predefined time. When the investment capital is acquired in the smart contract, the investment is transferred to the RE company (step 3). The RE infrastructure can then be constructed (step 4). After the RE plant is installed, the community can consume electric energy and pay the previously calculated price per kilowatt hour which fits the requirements of the model. For each kilowatt hour consumed by the community, one asset token is transferred from the impact investors to the community (step 5). In this process, the 


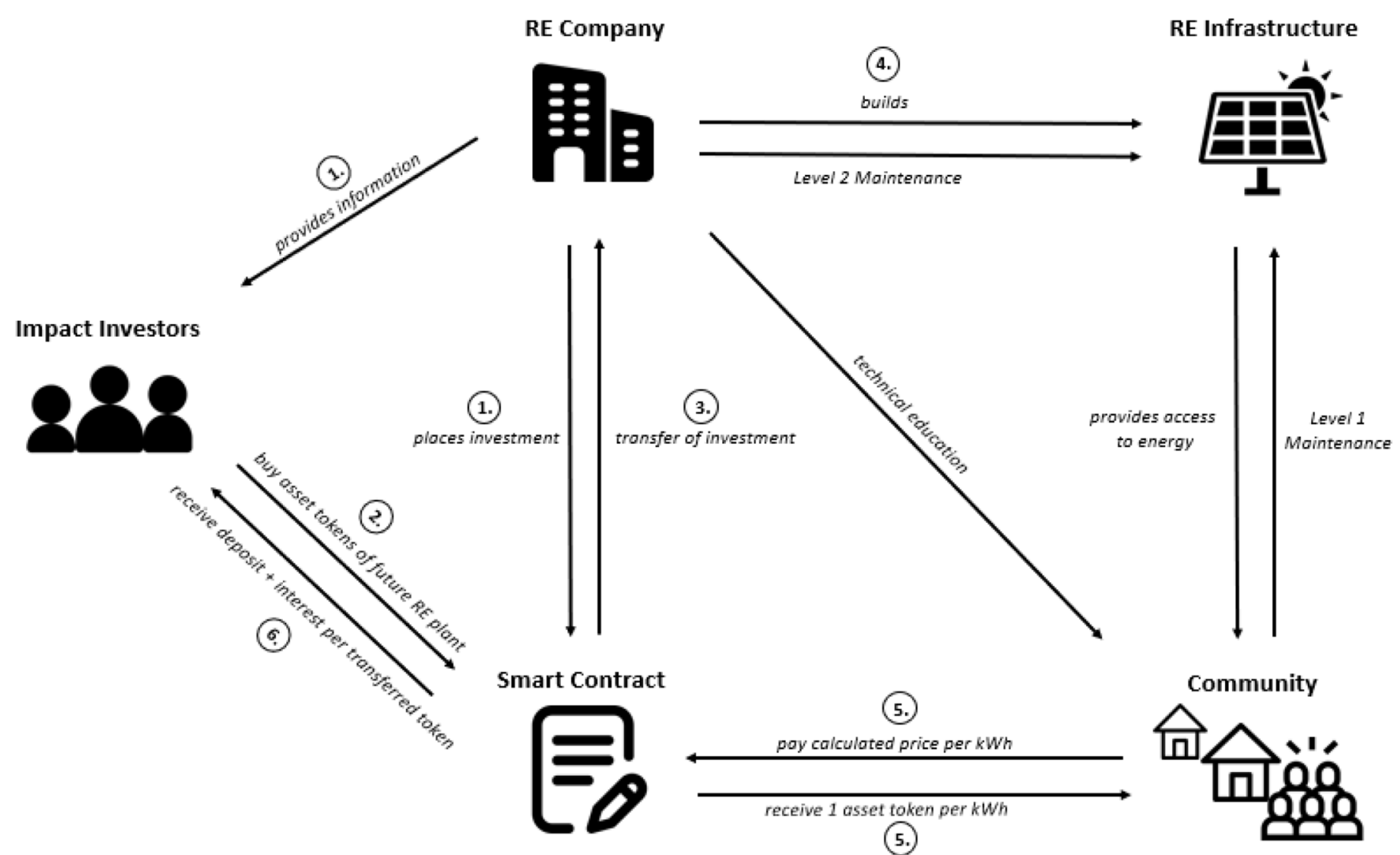

Fig. 4. Extension of CSOP model integrating blockchain technology.

ownership of the RE plant is transferred from the impact investors to the community over time. By the end of this process, the impact investors have regained their deposits including the previously defined interest rate (step 6). The $\mathrm{RE}$ plant is then completely owned by the community.

For this model to be completely sustainable, various factors must be considered. The RE plant needs maintenance, which in this model is divided into level 1 and level 2 maintenance. Level 2 maintenance is in this case defined by measures that are required to be executed by experts. Those can be employees of the RE company which constructed the RE plant. Level 1 maintenance should be executed by members of the community. To establish the expertise for executing level 1 maintenance, educational measures for the community members are required. Further work will need to be done to define these measures in detail, but it is desired to establish an educational system that provides jobs for the community and guarantees the independent handling of smaller issues regarding the $\mathrm{RE}$ plant. The costs for potential maintenance measures must also be calculated in advance and be integrated in the price for asset tokens for the impact investors. Maintenance is an enormous factor in RE projects, in Africa, for instance, it is considered one of the biggest problems of the solar energy sector [21]. The technical education integrated into the presented model aims to establish maintenance capacities in the community and thus ensure a sustainable long-term use of the infrastructure. Reducing maintenance costs and participation of the community are additional values of this process. When developing energy infrastructure in Africa, core issues to be addressed include maintenance, capacity building methods and service [22].

A key aspect of the model is the holistic perspective, which includes the phases before, during and after the life cycle of the infrastructure. Before installing the RE plant, a precise analysis of the stakeholders is required. Interests and specifications of all actors, most importantly of the community, must be considered. Educational measures to implement expertise for level 1 maintenance in the community must be completed before the RE plant starts operating. During the life cycle, information in many areas, for example in acceptance of the community and technical issues of the RE plant must be collected and evaluated. When the RE plant is fully transferred to the community, additional profit must be collected in a fund which can also be integrated in the smart contract. This can contribute to the installation of a new RE plant after the life cycle of the first installed plant.

\section{Conclusion}

In this paper, a layer was added to the original CSOP model by integrating blockchain technology to increase efficiency and automate processes. Furthermore, this model has been improved by introducing the key element 
of ownership transfer over the lifecycle of the energy infrastructure within the next generation CSOP for impact investment concept. Applied in energy infrastructure projects, the approach could be an enabler for scalable, transparent investment systems in developing countries. By implementing blockchain technology, the efficiency of financial flows is increased, incentivising investors to buy shares of energy infrastructure projects. In comparison with the original CSOP model, the next generation impact investment model developed in this paper has various additional advantages, e.g. the participation and education of community members, the creation of incentives for investors, and a long-term development perspective for communities without access to electric energy. Considering these aspects, the model has the potential to initiate new sustainable energy infrastructure projects and to stimulate the sustainable development of current projects in developing countries.

Further research regarding the model could concentrate on two fields. First, the model must be evaluated in detail to achieve the optimum value for the investors, the community and the RE company. Costs for the construction and maintenance of the energy infrastructure as well as for the architecture of the technological ecosystem have to be calculated to estimate the price for energy consumption. Second, the technical architecture including the programming of the smart contracts must be prepared. This measure is an important step, providing the foundation for a universal application of the system in different surroundings.

A further step for this model is the practical implemenation of a project on the Don Bosco Renewable Energy Campus in Tema, Ghana. The authors aim to develop a framework including all relevant stakeholders as a blueprint and catalyst for renewable energy infrastructure projects in the future. This approach will include NGOs as major actors of the model. In this research work, concrete results will be generated for the further development of the next generation CSOP impact investment model.

Acknowledgments. The research work published in this paper is conducted within the project "MoNaL - Mobility sustainably thought through the life cycle" (16EXI4011A) supported by the German Federal Ministry for Environment, Nature and Nuclear Safety as part of the program Export Initiative Environmental Technologies. We are very grateful for the important preparatory work of David Vogel, Leo Wilms and Lena Fuhg, who contributed to the idea of a blockchain-integrated CSOP model as part of a project study. We would also like to thank Tanja Romahn and Frank Vossnacker from Siemens Energy, who inspired us during our research work.

\section{References}

1. Our World in Data, Emissions by Sector (2020) https:// ourworldindata.org/emissions-by-sector (accessed 25th November 2020)
2. A. Sayigh, Up-date: renewable energy and climate change, Renew. Energy Environ. Sustain. 6, 13 (2021)

3. J. Lowitzsch, The CSOP-financing technique: origins, legal concept and implementation, in Energy Transition (Springer, 2019), pp. 163-183

4. SCORE, 'Co-own. Prosume. Renew. Supporting Consumer Ownership in Renewable Energies' (2021). https://www. score-h2020.eu/about-us/about-score/ (accessed Oct. 06, 2021)

5. International Renewable Energy Agency (IRENA), Ed., Scaling up Renewable Energy Deployment in Africa: Detailed Overview of IRENA's Engagement and Impact (2020). Available: https://www.irena.org/-/media/Files/ IRENA/Agency/Publication/2020/Feb/IRENA_Africa Impact_Report_2020.pdf?la=en\&hash $=$ B1AD82 8 DFD $\overline{7} 7$

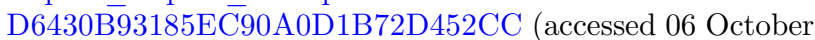
2021)

6. A.J. Reid, J.L. Brooks, L. Dolgova, B. Laurich, B.G. Sullivan, P. Szekeres et al., Post-2015 sustainable development goals still neglecting their environmental roots in the anthropocene, Environ. Sci. Policy 77, 179-184 (2017)

7. G. Schwerhoff, M. Sy, Financing renewable energy in Africa key challenge of the sustainable development goals, Renew. Sustain. Energy Rev. 75, 393-401 (2017)

8. https://www.exportinitiative-umweltschutz.de/de/projekte/ monal

9. E.I. Castellas, J. Ormiston, Impact investment and the sustainable development goals: embedding field-level frames in organisational practice, Entrepreneur. Sustain. Dev. Goals 87-101 (2018)

10. IEA, World Energy Outlook 2020 (OECD Publishing, Paris, 2020)

11. C. Oji, O. Soumonni, K. Ojah, Financing renewable energy projects for sustainable economic development in Africa, Energy Proc. 93, 113-119 (2016)

12. A. Franco, M. Shaker, D. Kalubi, S. Hostettler, A review of sustainable energy access and technologies for healthcare facilities in the Global South, Sustain. Energy Technolog. Assess. 22, 92-105 (2017)

13. J. Lowitzsch, Consumer Stock Ownership Plans (CSOPs) The Prototype Business Model for Renewable Energy Communities, Energies 13, 1-24 (2019)

14. D. Yaga, P. Mell, N. Roby, K. Scarfone, Blockchain technology overview, National Institute of Standards and Technology (2018)

15. V. Brühl, Bitcoins, Blockchain und Distributed Ledgers, Wirtschaftsdienst 97, 135-142 (2017)

16. P. Treleaven, R.G. Brown, D. Yang, Blockchain technology in finance, Computer 50, 14-17 (2017)

17. J. Weking, M. Mandalenakis, A. Hein, S. Hermes, M. Böhm, H. Krcmar, The impact of blockchain technology on business models-a taxonomy and archetypal patterns, Electronic Markets 5, 1-21 (2019)

18. W. Prinz, A. Schulte, Blockchain und Smart Contracts Technologien, Forschungsfragen und Anwendungen. Fraunhofer FIT (2017) p. 1-50

19. R.M.A. Latif, M. Farhan, O. Rizwan, M. Hussain, S. Jabbar, S. Khalid, Retail level Blockchain transformation for product supply chain using truffle development platform, Cluster Comput, 1-16 (2020)

20. M. Warkentin, C. Orgeron, Using the security triad to assess blockchain technology in public sector applications, Int. J. Inf. Manag. 52, 102090 (2020) 
21. A.A. Adenle, Assessment of solar energy technologies in Africa-opportunities and challenges in meeting the 2030 agenda and sustainable development goals, Energy Policy 137, $111180(2020)$
22. J. Kenfack, J. Voufo, P.S.N. Ekam, J.K. Lewetchou, U. Nzotcha, Overcoming local constraints when developing renewable energy systems for the electrification of remote areas in Africa', Renew. Energy Environ. Sustain. 5, 1 (2020)

Cite this article as: Martin Fortkort, Sebastian Finke, Semih Severengiz, Blockchain-Based Consumer Stock Ownership Plans (CSOP) As a Catalyst For Impact Investments in Sustainable Energy Infrastructure, Renew. Energy Environ. Sustain. 6, 43 (2021) 